\title{
REAR BATTLE DEFENSE AND \\ ARTILLERY FIRES
}

\author{
A MONOGRAPH \\ BY \\ Major Clarence Neason \\ Field Artillery
}

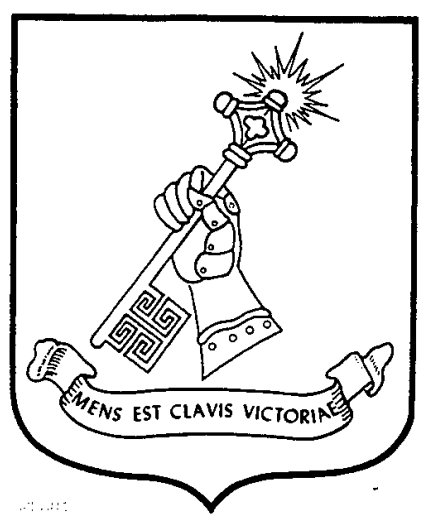

School of Advanced Military Studies

United States Army Command and General Staff College

Fort Leavenworth, Kansas

First Term AY 97-98

Approved for Public Release Distribution is Unlimited

DTIC QUATHY THSPEUTID 3 
Public reporting burden for this collection of information is estimated to average 1 hour per response, hreluoding the time for reviewing tnstructions, searching existing data sources, colthering and maintaining the dala needed, and completing and reviewing the collection of inlormation. Send comments regarding this burden estimate or any other aspect of this Davis Highway, Suite 1204, Altington, YA 22202-4302, and to the Office of Mashingion Headguarters Services, Directorate for Inlormation Operations end Reports, 1215 Jelferson Davis Highway, Sutte 12O4, Afington, VA 22202-4302, and to the Office of Management and Budget, Papenwork Reduction Project (0704-0188), Washington, DC 20503.

\begin{tabular}{|l|l|l|}
\hline 1. AGENCY USE ONLY (Leave blank) & $\begin{array}{c}\text { 2. REPORT DATE } \\
\text { 18 December } 1997\end{array}$ & $\begin{array}{l}\text { 3. REPORT TYPE AND DATES COVERED } \\
\text { MONOGRAPH }\end{array}$ \\
\hline
\end{tabular}

4. TITLE AND SUBTITLE 18 December 1997 MONOGRAPH

Rear Betle Deferse and Artillery Fores

6. AUTHOR(S)

$$
\text { Major Clareme Neoson Ji }
$$

7. PERFORMING ORGANIZATION NAME(S) AND ADDRESS(ES)

SCHOOL OF ADVANCED MILITARY STUDIES

COMMAND AND GENERAL STAFF COLLEGE

FORT LEAVENWORTH, KANSAS 66027

9. SPONSORING / MONITORING AGENCY NAME(S) AND ADDRESS(ES)

COMMAND AND GENERAL STAFF COLLEGE

FORT LEAVENWORTH, KANSAS 66027

\section{FUNDING NUMBERS}

8. PERFORMING ORGANIZATION REPORT NUMBER

\section{SUPPLEMENTARY NOTES}

12a. DISTRIBUTION / AVAILABILITY STATEMENT

DISTRIBUTION UNLIMITED

12b. DISTRIBUTION CODE

\section{ABSTRACT (Maximum 200 words)}

SEE ATTACHED

14. SUBJECT TERMS
Rear Bathle and Artilleiy

17. SECURITY CLASSIFICATION OF REPORT UNCLASSIFIED
:8. SECURITY CLASSIFICATION OF THIS PAGE UNCLASSFIED
19. SECURITY CLASSIFICATION 20. LIMITATION OF ABSTRACT OF ABSTRACT UNCLASSIFIED

10. SPONSORING / MONITORING AGENCY REPORT NUMBER 
ABSTRACT

REAR BATTLE DEFENSE AND ARTILLERY FIRES by Major Clarence Neason, Jr., USA, 46 pages

This monograph examines rear battle doctrine and artillery fires to determine the adequacy of doctrine as it relates to the use of artillery fires in the rear. It analyzes rear battle doctrine as a whole and as it pertains to the effective and or ineffective use of artillery to defeat rear area threats. Specifically, the focus will seek to extract and critique past techniques as well as propose a solution to aid in combating threats to the rear with artillery fires.

The doctrine for the rear battle operations as described in doctrinal manuals depicts a discrete approach to combating threats to the rear area. Additionally, the ad hoc nature of the employment of fires in the rear further impedes the efficient and effective defense of the rear area. This approach to rear battle operations while not self defeating, certainly hampers efficiency.

While fires in support of rear threats are provided on a contingency basis, the structure to use these fires, when they become available, must already be in place and thus a doctrinal change regarding the structure of the fires system in the rear is needed. Fires in support of the rear, just as elsewhere, must be planned and coordinated to maximize its effectiveness. The rear area as the sustaining base for the close and deep operations is critical to overall success and suggests a need for a permanent fire support organization in the rear. 


\section{SCHOOL OF ADVANCED MILITARY STUDIES}

MONOGRAPH APPROVAL

Major Clarence Neason, Jr.

Title of Monograph: Rear Battle Defense and Artillery Fires

Approved by:
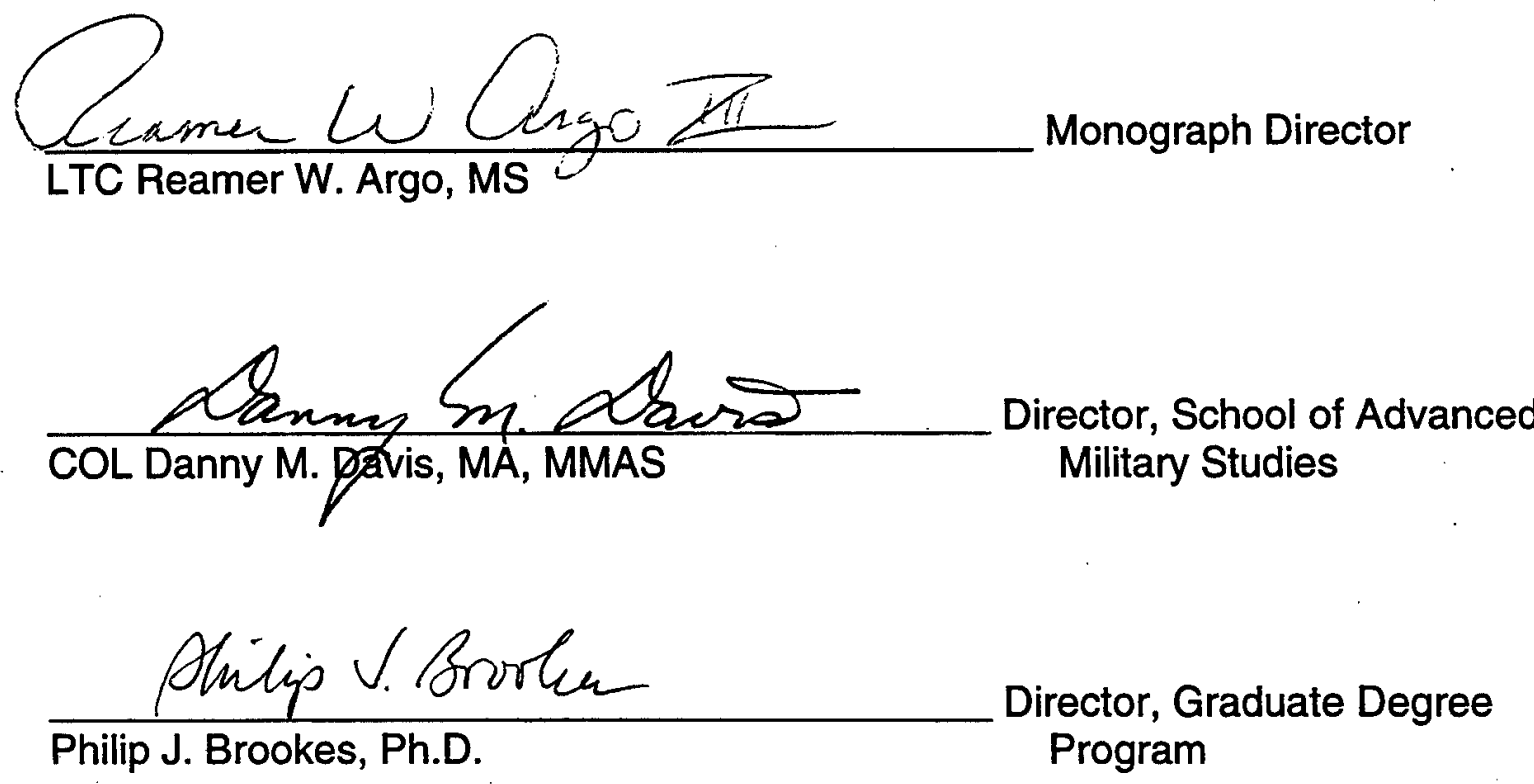

Accepted this 18th Day of December 1997 
ABSTRACT

REAR BATTLE DEFENSE AND ARTILLERY FIRES by Major Clarence Neason, Jr., USA, 46 pages

This monograph examines rear battle doctrine and artillery fires to determine the adequacy of doctrine as it relates to the use of artillery fires in the rear. It analyzes rear battle doctrine as a whole and as it pertains to the effective and or ineffective use of artillery to defeat rear area threats. Specifically, the focus will seek to extract and critique past techniques as well as propose a solution to aid in combating threats to the rear with artillery fires.

The doctrine for the rear battle operations as described in doctrinal manuals depicts a discrete approach to combating threats to the rear area. Additionally, the ad hoc nature of tive employment of fires in the rear further impedes the efficient and effective defense of the rear area. This approach to rear battle operatioris while not self defeating, certainiy hampers efficiency.

While fires in support of rear threats are provided on a contingency basis, the structure to use these fires, when they become available, must already be in place and thus a doctrinal change regarding the structure of the fires system in the rear is needed. Fires in support of the rear, just as elsewhere, must be planned and coordinated to maximize its effectiveness. The rear area as the sustaining base for the close and deep operations is critical to overall success and suggests a need for a permanent fire support organization in the rear. 
TABLE OF CONTENTS

I. Introduction.................

II. The Rear Area................5

III. Doctrine....................

IV. Fire Support in the Rear.........19

v. Analysis...................28

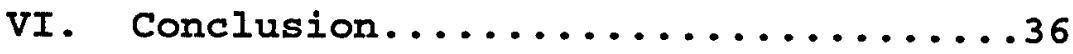

Endnotes......................40

Bibliography...................44 


\section{INTRODUCTION}

Rear operations may have little immediate impact on close ground operations, but are critical to subsequent operations, whether in exploiting success or recouping failure. At the operational level, rear operations focus on preparing for the next phase of the campaign or major operation. At the tactical level, rear operations underwrite the tempo of combat, assuring the commander the agility to take advantage of any opportunity without hesitation or delay. ${ }^{1}$

The battlefield organization of deep, security, close, rear, and reserve are all important, however, perhaps the most important is the rear where a commander maintains the ability to effectively influence both the deep and close fights. The rear area secures for the commander the freedom of action and continuous flow of logistics, personnel, equipment and ammunition to support successful mission accomplishment. The rear may be the force's center of gravity, its reservoir of strength and flexibility. The center of gravity as used here is intended to portray the essential nature of the rear area and its relationship to the entire battlefield: ${ }^{2}$ Clearly, the rear is an important 
area, if not the most important, yet it is easily neglected because of its spatial and time relationship to events on the battlefield. The rear area must not be viewed as a low maintenance area only to be attended to infrequently but rather as an area to be consistently monitored or one may put at risk the core of a unit's ability to fight. The rear is the base of operations, a fulcrum to work from, and the place most likely to be the catalyst for future success or failure. ${ }^{3}$ Notwithstanding the immense importance of the rear battle and its correlation to success or failure, there exists a doctrinal void. Surprisingly, little seems to be available to guide and assist the commander as he plans to protect and preserve his flexibility and freedom of action. Current doctrinal texts define the rear as that place behind the main battle area where supply, maintenance support, and command and control facilities are quartered ${ }^{4}$. The purpose of these organizations within this area is to provide freedom of action and continuity of operations to the maneuver commander by sustaining current operations and posturing the force for future operations. ${ }^{5}$. The rear area should be a relatively secure position since one's own forces or other friendly forces would have previously 
operated in it. Although, no area in an active combat environment is truly secure. The heart of a commanders' ability to exert his will on an opposing force stems from his resources in the rear, both fighting power and sustaining assets, and the flexibility it accords. The optimal situation in the rear affords the commander the ability to sustain his forces in contact, that is, the close fight, while affording him the capacity to interdict the enemy deep and inhibit his ability to sustain his forces in the close fight.

The battlefield suggests that the rear area is key to the commanders' ability to gain and maintain the initiative and subsequently exert his will on the enemy. A key to the commanders' ability to exert himself lies in the prosecution of the rear fight and the means available to that end. Admittedly, fires are a destructive force yet their use must be weighed against the potential undesirable effects of fratricide, collateral damage, and acquisition. Nevertheless, doctrinally there exists a void with regard to how one effectively employs fires to sustain the commander's freedom of action in the rear fight. This paper seeks, to reinforce the importance of the rear battle and some of the 
considerations necessary to integrate fires successfully. The topics that will be discussed in this paper are: the rear area; doctrine and rear fire support. Within this framework an analysis of fires will be conducted focusing on the following domains: the threat, the nature of the dangers in the rear; decision criteria, what should the commander use to determine which weapon to employ against a threat; control mechanism/C2, what structures are available to control the rear fight specifically with fires; the coordination process, what is the procedure and who should be coordinated with and does it expedite or inhibit effective and efficient attack of a target; munitions, what are the considerations; and risk, does the use of artillery fires expose the force to unacceptable hazard. The activities of the rear battle must be consolidated and illuminated to provide commanders with an effective framework from which to devise tactics, techniques, and procedures to successfully defeat rear area threats. 


\section{THE REAR AREA}

The rear area begins at the rear of the main battle area and extends through the communications zone. 6

Operations in the rear area are designed to sustain forces and provide for future operations thereby preserving the force's freedom of action.

The purpose of units in the rear are to contribute to current and future success. The rear is composed of elements that span the entire spectrum of organizations such as command and control, combat, combat support, and combat service support. While all of these elements may be present in the rear some may be only transitory while others are assigned to the rear. Normally, combat forces in the rear are there either awaiting deployment in the fight, returning from the fight, and or designated there to combat a specific threat. Combat support and service support units function in the rear area to support the close and deep operations and provide for rear area defense.

The capacity for effectively conducting defense within combat support and combat service support unit varies in that their primary focus is to provide specified technical support. The ability of a given support element to defend 
itself, is contingent on the type of threat it may face, their training level, weapons systems available, both individual, and crew served, and their personnel strength. The intent of this statement is not to debase soldiers in combat support or combat service support but rather to highlight the difficult nature of their task. The dual requirements of units in the rear to provide the needed technical support while simultaneously maintaining an aggressive self defense status are not wholly incompatible, yet, the reality is that one may detract from the other. Conversely, combat elements are better postured to deal with enemy threats. Combat elements possess the requisite training, weapons, and task organization to repel and or defeat enemy activities. Again, the purpose here is not to proclaim one type of element over the other but rather to portray the assets available and their inherent advantages and handicaps.

While force self protection is an inherent mission, combat support and service support units possess limited self protection capability yet their success with regard to self protection is essential. Nevertheless, there are two options regarding this situation, one is to commit forces to 
the rear or to accept risk and respond consistent with the level of threat posed and one's capacity. ${ }^{7}$

The rear battle principle of 'economy of forces' articulates our acceptance of risk in the rear so as to mass at the decisive point in the close and/or deep fight. ${ }^{8}$ Doctrine recognizes and accepts the notion that the rear battle represents a critical fight for the Army. However, doctrine acknowledges that while the "[fight] cannot be won solely by fighting the rear battle; but it could well be lost in the rear." ${ }^{9}$ The constraints in manpower resources edict that risk be accepted in the rear since the fight will be won in either the close or deep battle. This represents the Army's method of dealing with limited resources.

Risk is endemic in operations as well as all that we do. Despite this fact, and our acceptance of risk as consistent with the rear battle principle of economy of force we must seek to reduce its potential hazards. While risk is a reality, the critical nature of rear battle activities demand that thorough consideration be given to the rear to avoid catastrophic failure and ultimate defeat. Forces in the rear provide the very lifeline to those in the current battle. Rear battle activities provide freedom of 
action and continuity of operations by sustaining current operations and posturing the force for future operations. ${ }^{10}$

As a measure of reducing unit vulnerability doctrine emphasizes the maintenance of a high level of self protection. Training is the vehicle that allows units to acquire and sustain the capacity to, at a minimum, contain a threat until assistance arrives and or at best to defeat the threat. Again, because of the critical nature of rear area activities and the limited forces in a given theater it is essential that planning for the rear fight and command and control structures be thoroughly considered and proactively employed. The inherent vulnerabilities, lack of combat power, and acceptance of risk must be compensated for, less we forfeit flexibility, agility, and the means to sustain the close and deep battle.

Enemy forces will seek to minimize and or eliminate our ability to leverage rear area assets. As a means to this end they will attack using a host of measures ranging from conventional to unconventional forces in our rear. Additionally, future threats to the rear will no longer solely consist of independent 'regular' elements but rather threats will appear as 'irregular' elements such as 
saboteurs, terrorists, and disaffected partisans. Specifically, these threats will seek to defeat or disrupt command and control facilities, logistics activities, reserves and combat elements reconstituting.

The rear area is organized under the Rear Area Operations Center (RAOC) and utilizes the base and base cluster system as a means of combating threats. ${ }^{11}$ Doctrine identifies three types of threats categorized as levels 1-3. Generally, level one and two threats range from individual saboteurs to company size elements while a level three threat will be battalion size or larger. The base cluster defense system is designed to deal with level one and two threats with the assistance of early response forces normally, military police assets in the rear. Level three threats are beyond the capability of these forces and need external assistance from either the tactical combat force or other combat assets that may be residing in the rear area for various reasons. These threat activities may or may not be interrelated and the rear area must possess a capacity to deal with them individually or simultaneously.

Some of the problematic areas of rear operations are planning, command and control, communications, and movement 
control and terrain management. While these areas within rear operations are not all inclusive they are key to the success in rear operation.

Rear area activities are critical to success of the force. The ability to conduct proactive planning for rear area operations instead of reactive planning is critical. Some of the critical aspects of planning include intelligence preparation of the battlefield, the seamless integration of rear operations with the close and deep battle, and force allocation. ${ }^{12}$ Central to the idea of fighting successful in the rear is the acceptance of the notion of "one fight" merely partitioned to facilitate focus and control for the commander.

Command and control of rear operations must be established so as to facilitate coordinated and simple operations. While in concept this is simple, it is extremely difficult to accomplish given the tremendous diversity of the units in the rear ranging from maneuver reserves to combat service support elements.

The establishment of an effective communications system is one of the most critical, if not the most critical, aspects of rear operations. Effective communications in the 
rear facilitates control by affording the dissemination of information required both up and down and laterally for the conduct of rear combat operations.

Movement control and terrain management in the rear is another important aspect of effectively conducting rear operations since the inability to adequately control and track movement severely hampers one's ability to coordinate an effective defense. While the plethora of units and activities in the rear make movement control and terrain management difficult, it must be mastered if rear operations are to be conducted in a cohesive and effective manner. Furthermore, rear operations may not be contiguous with the forward area (close fight), a problem which may complicate both protection and sustainment issues. Nevertheless, to prevent the diversion of assets from either close or deep operations fight the rear must maintain an ability to protect itself against all threats except the most serious (e.g. Level III). Commanders must continuously evaluate threats to their rear and devise and implement contingencies that minimize the impact that threat actions have on close and deep operations. ${ }^{13}$ 


\section{Doctrine}

Current doctrine stipulates that the essential elements to defeat enemy forces in the rear area are effective command and control relationships, command supervision, reliable communications, accurate intelligence, centralized defensive planning coupled with decentralized execution, reaction forces and an assessment of one's capabilities. ${ }^{14}$ The means of accomplishing these tasks are facilitated through the categorization of the threat in three levels and the use of bases and base cluster organizations. Bases as defined in FM 90-14, Rear Battle, are small defensible areas with a defined perimeter and established access controls. ${ }^{15}$ The base is the focal point for defensive planning in the rear against primarily level 1 threats. ${ }^{16}$ While there exist two higher levels of threat that may threaten the rear FM 90-14 states that these threats will be engaged with auxiliary elements and weapon systems such as MPs, artillery, and or a tactical combat force. ${ }^{17}$ Base clusters are groups of bases linked together to enhance security and facilitate the continuous uninterrupted support of combat forces. Within the rear area a provisional base cluster commander is designated to control each base cluster and is overall 
responsible for ensuring that the efforts of the base cluster are mutually supporting. Operations centers are established to facilitate effective and continuous twentyfour hour support. The Rear Area Operations Center (RAOC) is the hub of control for rear area activities and coordinates the efforts so as to attain maximum efficiency and effectiveness. The Rear Area Operations Center plans, coordinates, advises, and directs the execution of the rear battle. ${ }^{18}$ The Base Defense Liaison Team (BDLTs) is a key element that assists the RAOC with its mission. Base Defense Liaison Teams are assigned to the RAOC and they coordinate base defense and liaison between contiguous units. The Rear Area Operations Center is a separate and distinct organization from the combat elements that may be temporarily assigned to the rear area. The RAOC functions under the auspices of the Rear Battle officer appointed by the echelon commander based on the factors of METT-T to control the rear battle.

The types of threat that may seek to hinder and or totally impede rear battle operations are: 
Level I

- Enemy controlled agents activity

- Sabotage by enemy sympathizers

-Terrorism

Level II

-Diversionary/Sabotage operations

-Raids, ambush, and reconnaissance operations

- Unconventional warfare

Level III

- Heliborne, Airborne, and Amphibious operations

- Deliberate ground force operations

-Infiltrations ${ }^{19}$

These threat level activities are mutually or hierarchically related and only serve as a means of categorizing enemy activity to effectively defeat it.

Rear battle objectives as indicated in FM 90-14

are to:

1. Secure rear area facilities

2. Prevent or minimize disruption of combat

support and combat service support forward 
3. Prevent or minimize enemy interference with command, control, and communications

4. Provide unimpeded movement of friendly units throughout the rear area

5. Find, fix, and destroy enemy incursions in the rear area

6. Provide area damage control after an attack or incident $^{20}$

Consistent with these objectives, doctrine outlines the following principles as a method to accomplish its objectives: 1) unity of effort - facilitates effective force protection and uninterrupted support; 2) economy of force entails combat support and combat service support units maintaining a posture to defend themselves and contain the threat until reaction forces arrive to assist as well as minimizing any attempts to disrupt their support operations; 3) responsiveness - is the ability to immediately react and deploy sufficient combat power and resources to destroy the enemy and minimize damage. ${ }^{21}$

Nevertheless, a seemingly dichotomous relationship exists between support functions and defense in the rear area. The combat support and combat service support soldier 
in the rear area is primarily focused on providing a specific service and is less skilled at performing their secondary yet crucial task of self defense. While, the two missions of, support to the force and rear area defense can come into conflict, they are both critical and must be accomplished. This problem is exacerbated by doctrine in that each unit in the rear is primarily responsible for its own security. The fix for this situation, albeit a weak one, is the concept of bases and base clusters. The notion of base and base cluster defense as an effective tool not only conflicts with the primary purpose of combat support and combat service support organizations not to mention overlaying a tactical chain of command on its existing technical one. While clear lines delineate the function of these two chains, the implementation of one generally causes a degradation of operations of the others' abilities.

Current rear battle doctrine appears to be passive, a quality which forfeits initiative and taking the battle to the enemy. The nature of this doctrinal philosophy inherently hampers the force's ability to dictate the terms of the battle to the enemy. This weakness in doctrine inhibits the commander's ability to truly dominate the enemy 
in time, space, and 'resources'. The enemy's ability to attack friendly forces in depth poses grave problems and threatens our ability to exploit weaknesses efficiently given this reactive posture. The most effective response to threats to the rear rely on our ability to assess the threat and respond appropriately in an aggressive proactive manner. While doctrine recognizes the need to sustain forces in contact and simultaneously provide for future operations there seems to exist potentially contradictory guidance regarding the potential conflict between self defense and support/technical responsibilities. Contemporary threats suggest that terrorists, irregular forces, and special operation elements will seek to neutralize our ability to leverage overwhelming combat power and resources at the decisive points in the deep and close fight. In light of this potentially significant problem, it is perhaps the rear battle that needs to be focused on to preserve the ability to win both the current and future fight. The rear is the base of operations, a fulcrum to work from. While efforts of the rear contribute indirectly to the force's overall success, its importance should nevertheless not be minimized. Despite the passive nature of our rear battle 
doctrine it is problematic for our adversaries in that it seeks to deprive them of the ability to effectively fight by generating and sustaining the momentum for friendly forces. Hence, enemy forces in an effort to negate this advantage, will deploy elements throughout the depth of our sector. Enemy forces' evolving patterns of fighting suggest that multiple assets, both regular and irregular, of increasing sizes will be deployed to thwart our ability to gain and retain the initiative in the close and deep fights. The multiplicative effect of the assets in the rear are staggering and potentially overwhelming. Nevertheless, the ability to employ these assets are woefully inadequate. Current rear battle doctrine lacks unifying coherence that prioritizes efforts through consolidation and deconfliction. Combat support and combat service support elements are primarily focused on functional missions and have limited abilities to assist combating threats without severe degradation in their support operations. 


\section{Fire Support in the Rear}

The employment of indirect fires in the rear is one of the most responsive means a commander has to attack targets that pose a direct high level threat to rear operations and an indirect threat to overall operations. Fire support in the rear is usually provided on a contingency basis. Seldom will there be enough fire support assets to meet the needs of the entire battlefield simultaneously. ${ }^{22}$ Nevertheless, there may be times when artillery is positioned in the rear to combat a specific threat. In cases when fire support assets are positioned in the rear, they will require an on order mission since artillery is never held in reserve.

The use of artillery in the rear must be carefully planned so as to avoid collateral damage and fratricide. Critical to the effective use of artillery in the rear are planning, coordination, and fire support coordination measures. While these issues are not new to the fire support planning process they do present some unique situations. The diverse and functional nature of the environment of the rear demands it be analyzed differently than the close and deep battle. The close and deep battles represent the efforts of commanders within these respective 
areas of operation while the rear's multifunctional nature despite serving a singular aim may be at odds. The dilemma facing forces in the rear area is between assisting in rear area protection and providing continuous uninterrupted support. The issue here is the attainment of balance since both tasks are mutually dependent. The sustainment of support to forces in the close and deep battle rests on the rear's ability to protect itself and simultaneously provide the necessary support to ensure forces can maintain their freedom of action and flexibility.

Fire support is the collective and coordinated use of indirect fires weapons, armed aircraft, and other lethai and non-lethal means in support of a battle plan. Fire support planning and coordination exist at all levels throughout the depth and breadth of the battlefield. The purpose of fire support is to aggressively seek out targets whose destruction will degrade the enemy's effort and enable the commander to accomplish the mission.

The writings of Clausewitz provide guidance for the conduct of rear operations when he articulates that "...the aim of the commander in...battle is to expedite the decision" ${ }^{23}$ that is to successfully subdue the enemy with 
every asset at his disposal. Fires in the rear compliment this aim by ensuring continuous support and thereby securing flexibility in the close and deep battle.

While the fire support system is a single entity it is composed of a diverse group of systems. The methods of employing individual fire support systems vary yet their aim is singular and focused through the commander's battle plan. In the end, the goal is to effectively employ all fire support assets on the enemy in order to defeat his efforts. The ability to employ all available fire support systems and to integrate and synchronize their effects rely on planning and coordination. Fire support planning and coordination is the linchpin of the fire support system. Planning and coordination orchestrates fire supports assets together on a common path to maximize the commander's battle plan. The end product of these efforts is a highly responsive system that provides both the means to adequately attack targets with the most suitable weapon system available and the safeguarding of assets.

The employment of artillery fires in the rear area is an effective means of responding to significant threats (i.e. level II or III). However, it is essential to clear 
fires prior to attacking targets to minimize and or eliminate possible collateral damage or fratricide to friendly units and assets. Surprisingly, the issue of clearing rear fires is not addressed in depth in doctrinal manuals.

Fire support coordination measures are designed to facilitate the rapid attack of targets while simultaneously providing a measure of safety. The use of fire support coordination measures in the rear vary from their use in the close and deep battles.

The primary difference between fire support coordination measures used in the rear and those in the close and deep fight are who is authorized to implement them and the restrictions associated with them. ${ }^{24}$ The establishing authority is the specific rear area commander with an area of operation/responsibility. Doctrinally, only commanders, who own turf can establish fire support coordination measures. The rear, unlike the close and deep battle areas, is established in a system of bases and base clusters and the commander of a base does not technically have ownership of the area he occupies. ${ }^{25}$ The base commander in the rear is merely a tenant in the larger 
scheme. The rear as a whole is the responsibility of the overall maneuver commander. ${ }^{26}$ The following suggest some of the fire support coordination measures that may be used to coordinate rear area efforts.

A restricted fire area may be used along major supply routes, bases, and base clusters. The purpose of a restricted fire area in this fashion is that no fires would be allowed in the are unless requested by the implementing agency. The benefit of this measure is that it facilitates fires in support of the area without the need for additional clearance procedures. Additionally, the restriction on the RFA can be extremely specific, in that the commander can restrict certain munitions such as scatterable mines. However, the restriction of these munitions can be later rescinded and employed as appropriate as dictated by the situation and the level of risk the commander is willing to assume. The use of this measure facilitates the safeguarding of friendly resources by regulating fires in an area while not unduly inhibiting operations. ${ }^{27}$

No fire areas can be designated around key facilities and population centers. The use of this measure is to protect key assets by prohibiting fires or their effects in 
a designated area. Nevertheless, there are exceptions to the rule when the establishing headquarters temporarily approves fires in the are on a mission by mission basis or when fires are employed in self defense. ${ }^{28}$

Restricted fire lines are used to safeguard converging friendly forces. For example, this measure would be used when employing the tactical combat force (TCF) in the rear. Additionally, this measure is designated by the common commander among the converging forces. ${ }^{29}$

Free fire areas would be used around identified enemy forces and potential landing zones, lodgments, and drop zones. This measure is the most permissive in nature and streamlines the attack of targets since it neither requires prior cocrdination nor restrictions on muritions. ${ }^{30}$

An illustrated example of the use of the above mentioned fire support coordination measures is depicted on the next page. ${ }^{31}$ The diagram depicts a division rear area when an air assault force has been inserted. The rear area operations center, the command and control node for rear operations, has authorized the use of indirect artillery fires and committed the TCF to destroy the threat. The 


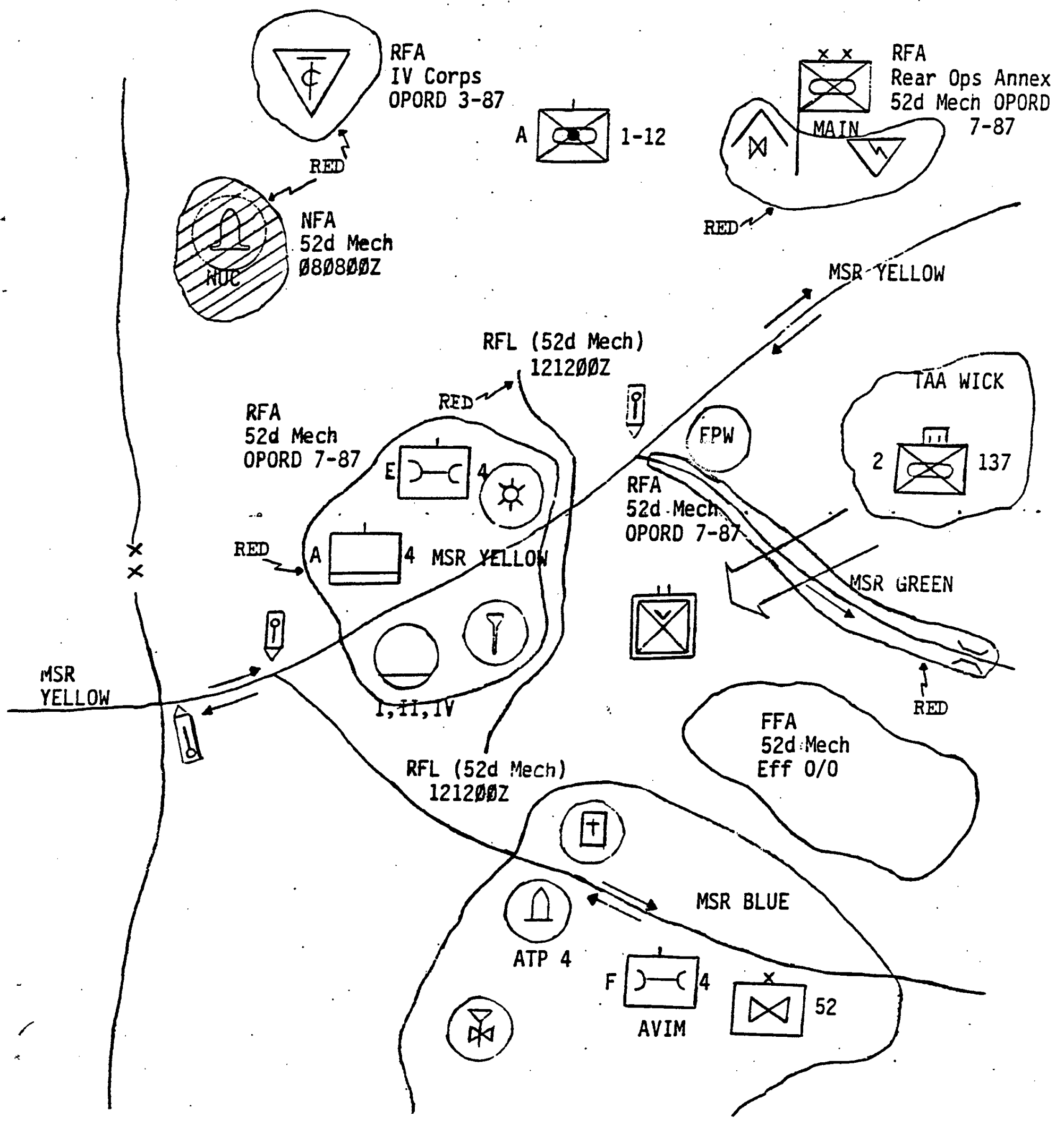

Example of Fire Support Coordination Measures in the Rear 
diagram is intended to illustrate the use of fire support coordination measures in the rear and is not all inclusive.

Doctrinally, the use of fires in the rear is difficult at best given the independent and discrete nature of the many rear area activities. The problem is further compounded by the fact that fire support organizations in the rear may have to be formed on an ad hoc basis. ${ }^{32}$ The importance of the rear to both the close and deep fight suggests a need for a permanent fire support organization with the necessary assets to combat any potential threat: without diluting the efforts of the close or deep areas. "A threat to the rear can,.....make a defeat more probable, as well as more decisive". ${ }^{33}$ Success in the rear may not directly determine the fate of the close and deep operations. However, its failure will certainly hinder future operations.

A review of several current rear fire support standard operating procedures (SOPs) further detail the faulty structure available to employ fires in the rear. For example, the literature strongly articulates the importance of fires yet no permanent structure is devoted to its cause. Indirect fires, the most responsive all weather system, is 
relegated to the aggressive and innovative means of whoever is available. While it is commendable that some forethought is being devoted to how fires will be implemented, surely such an ad hoc system can only be marginally successful. The problem with implementing fires in the rear is not a unit problem but rather a doctrinal problem. Doctrine of the future should allocate the appropriate personnel to man a fires structure to repel a level II or III threat efficiently. 


\section{Analysis}

The doctrine for the rear battle operations as described in doctrinal manuals depicts a discrete approach to combating threats to the rear area. This approach to rear battle operations while not self defeating, certainly hampers efficiency. The analysis of rear battle operations will focus on the use of fires in its capacity to assist in defeating threats to the rear. The means to this end is an examination of fires from the perspective of command, control, and communications mechanisms, the coordination process, clearance procedures, munitions effects, and the risks to rear assets.

The rear as the base of operations must be an integral component of the battle plan and not an after thought to be resourced with whatever is left or, we risk forfeiture of our ability to truly leverage our vast industrial capacity. The rear is perhaps the true source of a force's current energy and its potential energy. While both the latent and potential energy of the rear is an acknowledged doctrinal precept, we get overly occupied with the planning for the close and deep battles to the neglect of the rear. The activities of the rear and their initial benign nature seems 
to lure us into relegating rear events as easy fixes -

things that can be put off while the important business of planning for the deep and close fight consumes us. Nevertheless, Clausewitz' sage advice warns us that "everything in war is very simple, but the simplest thing is difficult" ${ }^{34}$ and we must avoid the trap of relegating rear operations to lesser important status or prepare ourselves to pay the price for this neglect.

The plan for defense of the rear is premised on the concept of bases, base clusters, the rear operations center, and the tactical combat force. Elements stationed in the rear are positioned so that they provide mutually supporting perimeter fires to repel a threat. While elements in the rear do possess the ability to defend themselves their capacity is limited hence, anything more than a low level threat (level I or II) presents a potentially impossible foe to defeat.

Units in the rear under attack are faced with two chains of command; one, technical and the other, tactical, a problem which further complicates the problem of effectively combating a threat. The initial actions of rear elements are designed to repel and or defeat a threat using its 
organic resources. If this method is ineffective the base cluster concept is utilized whereby a request is made to the rear area operations center for assistance. Next, a decision will be made as to whether the TCF will be committed. The problem with this scenario is that it assumes that elements in contact will be able to sustain themselves until the TCF is committed. The concept of having two command channels to coordinate effective security seems inherently flawed and a violation of the principle of unity of command.

Unity of command as defined in 100-5 requires that all forces be placed under one responsible commander and that this single commander possess the authority to direct all forces toward a unified purpose. The current dual structure of the rear seems to give primacy to the technical structure given the functional focus of rear elements. While the support functions of rear units are important, we must eliminate this dual structure and treat units in the rear in the same manner as units in other areas and integrate the rear's technical and tactical functions under one command structure. The fusing of the technical and tactical command structures should not prove too difficult, since, their 
overall purposes are the same despite the seemingly incompatible nature of their activities. The goal of the technical structure is to ensure continuous, efficient support while the tactical structure seeks force protection and the defeat of the enemy. The nature of the technical and tactical functions are mutually dependent on one another and crucial to success in the rear. Rear battle doctrine seems to underscore an emphasis on control to the detriment of command as evidenced by dual technical and tactical chains. While activities of the rear are different, they are no more unique than the activities of the close and deep battle and must be fused under a single command structure for maximum effectiveness. The existing structure in the rear is passive and as such, it holds marginal potential for effectively repelling and or eradicating a threat.

The best methods lie in establishing a unity of purpose designed to carry the fight beyond the immediate vicinity of threatened assets and right to the enemy's strongholds and rallying points. ${ }^{35}$ A first step towards this end is the consolidation of rear's efforts into a singular command structure bound by the commander's purpose and not discrete functions. The technique for controlling and executing the 
close and deep operations, like the rear, involves multiple organizations performing multiple functions yet doctrine solves the problem of these wide ranging activities by providing a single commander. This same concept must be adopted for the rear to eliminate potential confusion and enhance effectiveness.

Another facet of rear activities that both complicates and erodes effective command and control is the additional layers of command and control within each base and base cluster. In theory, the use of these layers was seemingly to aid in the effective control of the many assets in the rear. Yet, their duplicative nature seems to further burden an already over taxed system by slowing it more. Again, the activities of the rear must be orchestrated from clear, simple, and singular command structure. Hence, the ad hoc nature of much of the rear area operations command structure should be eliminated in favor of a fixed structure. It is imperative that any command and control system both seek and promote flexibility and freedom of action to optimize efforts and a possible solution to this dilemma is standardization. ${ }^{36}$ 
Another issue critical to defeating high level threats to the rear is the effective employment of indirect fires. As previously stated, a key aspect of employing fires is the clearance process. The procedure for clearing fires in the rear is not addressed in detail in doctrine. Nevertheless, perhaps the most effective means available for facilitating the attack of targets while simultaneously providing safeguards for friendly forces and assets is the use of fire support coordinating measures. Additionally, the use of maneuver control measures can also facilitate the clearance process. Maneuver measures provide definitive responsibility for terrain by assigning ownership and thereby simplifying the clearance process within and between organizations. The use of fire support coordination measures in the rear differs from its use in the close and deep fight in the following two respects: (1) who the establishing authority is and (2) the more Iiberal nature of the use of the restrictive measures. Doctrinally, only maneuver commanders with an area of operation can establish fire support measures unlike base commanders who only facilitate terrain management in the rear area and do not in a doctrinal sense, own the land - Base commanders are merely 
tenants. Other positive means of effectively clearing fires include :

-use the best available method of target location -positive identification of the target as enemy -target attacked by an eyes on observer -coordination clearance of targets outside one's area ${ }^{37}$ The clearance process is vital to successfully limiting, if not all together eradicating friendly fire incidents and collateral damage in the rear.

A major consideration on the use of indirect fires in the rear is munitions effects. The responsiveness, availability, and reliability of indirect fires make it a favorite choice against any threat yet there are side effects. One of the primary considerations of employing indirect fires in the rear are the munitions effects. Indirect fire systems are area weapon systems and cover an area commensurate with the caliber of the system (i.e. $105 \mathrm{~mm}$ - 35 meters) unlike point systems whose effects are generally limited to the target it hits. The use of indirect fires in the rear must be considered with respect to potential side effects. While indirect fire may provide the necessary punch to defeat an enemy in the rear it may 
adversely impact on friendly operations. Additionally, some munitions may be prohibited in the rear either because of the blast effect or duration. Specifically munitions such as FASCAM and DPICM are probably not the most desirable in the rear because of the duration of the mines in the former and the high dud rate in the latter. While these munitions may be effective against denying the enemy a specified piece of terrain, it also denies it to friendly elements. In the end, to more effectively use fires, one must weigh its use against potential adverse impacts on friendly mission accomplishment.

Finally, the need for a permanent fire support structure is needed and acknowledged - the next step is to move beyond this stage and implement the necessary doctrinal changes. While fires in support of rear threats will continue tc be provided on a contingency basis, the structure to use these fires when they become available must already be in place. Fires in support of the rear, just as elsewhere, must be planned and coordinated to maximize its effectiveness. The team that seeks to accomplish this task should be formed from a permanment organizational structure. 


\section{CONCLUSION}

Our doctrine for fighting is premised on the activities of the rear and the flexibility it provides for the effective prosecution of the close and deep operations. The intent of this paper was to revisit the issue of fighting in the rear and some of the doctrinal dilemmas that may hinder the effectiveness and efficiency of rear operations. The two primary doctrinal shortfalls to activities in the rear are the dual tactical and technical command and control structure and the lack of a permanent fires network to defeat level II and III threats.

$$
\text { Prior to offering some solutions to assist with }
$$

eliminating some of the potential problems in the rear it should be restated that the rear must cease to be viewed as a separate entity of lesser importance than the close and deep operations. Doctrine acknowledges the importance of rear activities yet in practice we are lured into a state of benign, if not abject denial, of its importance because of the delayed nature of adverse impacts to close and deep operations. Rear operations are crucial to success and 
should maintain requisite planning parity with the other battlefield structures.

Threats to the rear today are more dangerous than ever before. During the Cold war the typical threat to the rear was centered on small organized 'regular' forces employing Soviet style tactics. Although the Post Cold war era has not eliminated this threat one is more likely to face 'irregular' forces such as terrorists, saboteurs, and disaffected partisans attacking its rear. While the composition of these elements suggest their size may cause them to be evaluated as level I, threats we must maintain the capacity to not only defeat them, but seek out and destroy their base of operations.

A method for effectively eliminating the potential confusion and delays associated with the dual technical and tactical command and control structure is to fuse these mutually dependent functions under a single commander and eliminate the redundant layers. Doctrine specifies that the overall maneuver commander is responsible for the rear as he is for the close and deep battle hence there is no need for separate technical and tactical chains. 
The issue of fires in the rear poses many dilemmas ranging from munition selections, clearance procedures, and risk to name a few. Nevertheless, the most significant problem to effectively using fires in the rear is the lack of mandated structure to plan, coordinate and execute fire support. Again, doctrine acknowledges that non organic fires will be formulated on an ad hoc basis to combat level II and III threats. Nevertheless, a fire support structure and plan should already exist. Threats to the rear will always exist and we must be prepared to deal with them less we relegate an already vulnerable area to further disadvantage.

In conclusion, rear operations doctrine should be reevaluated and refined to ensure we posture the valuable assets in the rear for success.

If the recent past provides any clue to the future of warfare, it seems likely that two themes will recur with unsettling regularity. First, wars ... will flourish, as poor but often well-armed states seek to dominate their neighbors or crush internal unrest by force of arms. Second, ... armies increasingly will find themselves involved in such conflicts, unprepared... ${ }^{38}$ 
The likelihood for increased rear activities grows proportionally with that of lesser developed countries vying for status with the United States. While the United States may not face a peer competitor in the next decade we will certainly face attacks by rogue entities against our national interests. The future combat environment perhaps implies an end to the rear as we know it, and depicts an environment where the rear is everywhere. 


\section{ENDNOTES}

1. Department of the Army, Field Manual 100-5

Operations. (Washington: U.S. Government Print Office, 5 May 1986), p. 20. While this quote is taken from an earlier version of FM 100-5 the premise it advocates is supported in the ' 93 edition of FM 100-5 albeit in different terminology.

2. Carl Von Clausewitz, On War, edited and translated by Michael Howard and Peter Paret, (Princeton University Press, Princeton New Jersey, 1984), p. 595-600. The use of the concept of a center of gravity is a result of the author's interpretation Clausewitz' theoretical concept and its application to the rear as discussed in the section of On War titled War Plans.

3. Marshall, S.L.A., Men Against Fire. (Gloucester, Massachusetts, 1978) p. 186-187. It should be noted here that this reference is the result of the author's interpolation of Marshall's discussion of both rear activities and the reserve.

4. Department of the Army, Field Manual 90-14 Rear Battle. (Washington: U.S. Government Print Office, 10 June 1985), Chapter 2, p. 1 .

5. Department of the Army, Field Manual 100-5 Operations. (Washington: U.S. Government Print Office, 5 May 1993), Chapter 6, p. 15.

6. Department of the Army, Field Manual 90-14 Rear Battle. (Washington: U.S. Government Print Office, 10 June 1985), Chapter 2, p. 1 .

7. This is the result of the analysis of several doctrinal manual and common sense. Although only two options are depicted one could easily add other however, the author chose those cited as perhaps the most useful for this discussion.

8. Department of the Army, Field Manual 90-14 Rear Battle., (Washington: U.S. Government Print office, 10 June 1985), Chapter 2, p. 3 . 
9. Ibid., p. i.

10. Department of the Army, Field Manual 100-5

Operations., (Washington: U.S. Government Print Office, 5 May 1993), Chapter 6, p. 15.

11. Department of the Army, Field Manual 90-14 Rear Battle., (Washington: U.S. Government Print Office, 10 June 1985), Chapters 3 and 4. These two chapter discuss both the command and control and base defense operations for the rear battle.

12. Center for Army Lessons Learned Bulletin 2-86, Focus on Rear Operations. (Fort Leavenworth, KS., November 1986) p.10.

13. Department of the Army, Field Manual 100-5

Operations., (Washington: U.S. Government Print Office, 5 May 1993), Chapter 6, p. I5.

14. Department of the Army, Field Manual 90-14 Rear Battle., Chapter 2, p. 4.

15. Ibid., Chapter 4, p.2.

16. Ibid., Chapter 4, p.2.

17. Ibid., Chapter 4, p.2.

18. Ibid., Chapter 3, p. 13-16.

19. Department of the Army, Field Manual 71-100 Division Operations. (U.S. Government Printing Office, 1996) p. 2-17. Additional discussion of the Rear area threat levels can be found in FM 90-14, Chapter 1, and FM 6-23-30 Chapter 4, p. 19-20.

20. Ibid., Chapter 2, p. 2-3.

21. Ibid., Chapter 2, P. 3-4.

22. Department of the Army, Field Manual 6-20 Fire Support in The Airland Battle. (Washington: U.S. Government Printing Office, 17 May 1988) Chapter 3, p. 11. 
23. Carl Von Clausewitz, on War, edited and translated by Michael Howard and Peter Paret, (Princeton University Press, Princeton New Jersey, 1984), p. 531.

24. Center for Army Lessons Learned Bulletin 2-86, Focus on Rear Operations. (Fort Leavenworth, KS., November 1986) p.17.

25. This point is both implicit and explicit in several of the doctrinal manuals and Lessons Learn Bulletins hence, the author deems it more accurate to credit doctrine in general rather than a specific source.

26. Department of the Army, Field Manual 90-14 Rear Battle., Chapter 3, p. 1 .

27. Department of the Army, Field Manual 6-20-30 Fire Support for Corps and Division Operations. (Washington: U.S. Government Printing Office, 18 October 1989) Chapter 4, p. 23.

28. Ibid., Chapter 4, p. 23.

29. Ibid., Chapter 4, p. 23.

30. Ibid., Chapter 4, p. 23.

31. Center for Army Lessons Learned Bulletin 1-87, Rear operations. (Fort Leavenworth, KS., November 1986) p.19.

32. Department of the Army, Field Manual 6-20 Fire. Support in The Airland Battle. (Washington: U.S. Government Printing Office, 17 May 1988) Chapter 3, p. 11.

33. Carl Von Clausewitz, on War, edited and translated by Michael Howard and Peter Paret, (Princeton University Press, Princeton New Jersey, 1984), p. 233.

34. Ibid., p. 119.

35. Harned, Major Glenn M. "Offensive Rear Battle." Military Review. Vol 66 (February 1986), p. 30-35. 
36. Department of the Army, Field Manual 100-5 Operations. (Washington: U.S. Government Print Office, 5 May 1986), P. 21-22.

37. White Paper: Clearance of Fires in the Close Fight. (Fort Sill Oklahoma., October 1993), p. 1-3.

38. Scales, , Robert H., Jr., Firepower in Limited War. (National Defense University Press, Washington, D.C., 1990), p. 235. 


\section{BIBLIOGRAPHY}

\section{Government Publications}

Department of the Army. Field Manual 6-20 Fire Support in The Airland Battle. U.S. Government Printing Office, 17 May 1988.

Department of the Army. Field Manual 6-20-2 Corps Artillery, Division Artillery, and Field Artillery Brigade Headquarters. U.S. Government Printing office, 7 January 1993.

Department of the Army. Field Manual 6-20-30 Fire support for Corps and Division operations. U.S. Government Printing Office, 18 October 1989.

Department of the Army. Field Manual 71-100 Division

operations. U.S. Government Printing Office, 1996.

Department of the Army. Field Manual 90-14 Rear Battle. Washington: U.S. Government Print Office, 10 June 1985.

Department of the Army. Field Manual 90-23 Rear Security Operations. U.S. Government Printing Office, 14 November 1989.

Department of the Army. Field Manual 100-5 Operations. Washington. U.S. Government Print Office, 5 May 1986.

Department of the Army. Field Manual 100-5 Operations. Washington. U.S. Government Print Office, 14 June 1993.

Department of the Army. Field Manual 100-15 Corps Operations. U.S. Government Printing Office, 1 June 1996.

\section{BOOKS}

Bellamy, Christopher D. The Evolution of Modern Land Warfare: Theory and Practice. New York, New York: Routledge 1990. 
Doughty, Robert. The Evolution of US Army Tactical Doctrine, 1946-1976. Fort Leavenworth, Kansas: Combat studies Institute, 1979.

Cavazos, R. E., Howell, M. D., Sinclair, C. B., Livsey, W. J., Majikas, D. J., McClure, A. E., Jr., Analysis of Fire and Maneuver in Vietnam June 1966 - June 1968. US Army War College, Carlisle Barracks, Pennsylvania., 1969.

Clausewitz, Car Von, On War. edited and translated by Michael Howard and Peter Paret Princeton, NJ: Princeton University, 1984.

Ott, David E. Vietnam Studies, Field Artillery, 1954- 1973. Washington, D.C., Department of the Army, 1975.

Krepinevich, Andrew. The Army in Vietnam. Baltimore, MD: Johns Hopkins University Press, 1986.

Romjue, J.L., From Active Defense to Airland Battle: The Development of the Army Doctrine, 1973 - 1982. Fort Monroe, VA: Training and Doctrine Command, 1984.

Scales, , Robert H., Jr. Firepower in Limited War. National Defense University Press, Washington, D.C., 1990.

23 Artillery Group Artillery Vietnam. U.S. Army Military History Institute, Carlisle Barracks, Pennsylvania., 1 June 1969.

\section{$\underline{\text { ARTICLES }}$}

"Fire Support Coordination Measures Used in Rear Operations" CALL Bulletin 1-87 Fort Leavenworth, KS., April 1987 p. 17-20.

"Focus on the Rear Battle." CALL Bulletin 2-86 Fort Leavenworth, KS., November 1986 p. 2-23.

Lavender, ILT Bryan N. "Rear Area Security: The Threat (Part 1)." Marine Corps Gazette, January 1985.

Lavender, 1LT Bryan N. "Rear Area Security: Countering the Threat." Marine Corps Gazette, February 1985. 
Harned, Major Glenn M. "Offensive Rear Battle." Military

Review. Vol 66 (February 1986): pp. 30-35.

House, Major John M. "Fighting in the Rear." Army

Logistician (November - December 1986), pp. 17-21.

Mooradian, LTC Moorad. "Rear Area Security With an 'Elastic FEBA'." Military Review (September 1978) pp.43-49.

White Paper: "Clearance of Fires in the Close Fight." Fort Sill Oklahoma., October 1993.

White, Samuel R. "Clearance of Fires." CALL Newsletter 97-11 Fort Leavenworth, KS., April 1997 p. 16-19.

White Paper: "Fire Support for Rear Operations." Fort Sill, Oklahoma Tactics and Combined Arms Department, unpublished.

\section{Monographs and Papers}

Burch, Linda G. "Deficiencies In Current \& Emerging Rear Battle Doctrine" Student Essay: Carlisle Barracks: US Army War College, 15 April 1985.

Eckert, Gregory M. "Command and Control of the Division Rear Battle." School of Advanced Military Studies, Monograph, Fort Leavenworth: CGSC 31 December 1985.

Gentilini, Raymond E. "The Rear Battle: A Maneuver Doctrine Dilemma" Student Essay: Carlisle Barracks: US Army War College, 14 May 1986.

Hooper, Thomas A. "The Principles of War and the Rear Area Protection: Have We Achieved Economy of Force?" School of Advanced Military Studies, Monograph, Fort Leavenworth: CGSC 17 January 1988.

Moulton, Richard D. "Rear Area Commanders Responsibility" Student Paper: Carlisle Barracks: US Army War College, 26 May 1985.

Sowa, P. "Rear Operations: Can We Execute The Doctrine?" 
Student Paper: Carlisle Barracks: US Army War College, 23 March 1987. 